\title{
Scientific Communication Skills: The Transition From Further Education To Higher Education In The UK.
}

Alun Rees, University of Portsmouth, UK

Myra Wilkinson, University of Portsmouth, UK

\begin{abstract}
The study investigates the development of scientific communication skills in Further Education (FE) and Higher Education (HE) students studying science in the UK. Perspectives are gained from students and staff in both sectors. Evidence suggests that a mis-match in expectations exits and the onus may be on HE to explore more effective and innovative ways of developing scientific writing skills in new entrants.
\end{abstract}

Keywords: science, communication skills, expectations.

\section{INTRODUCTION}

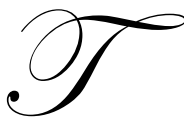

he rationale for the study is rooted in the general observation that many new entrants studying for a BSc degree in Higher Education (HE) experience difficulties in writing in conventional scientific formats, for example, the production of laboratory reports. Anecdotally this would appear to have a negative effect on student and staff morale. These difficulties appear to extend to students in Further Education (FE) and secondary school (hereafter referred to collectively as FE) from traditional entry routes such as A Level and BTEC as well as students entering from widening participation backgrounds. This problem was highlighted in the Roberts Review (2002) in which it was suggested that there were mis-matches between school level science subjects and related undergraduate courses thus preventing a smooth transition to HE. He also reported that many HE academic staff argue that current science syllabuses do not necessarily prepare students with the intellectual or conceptual knowledge required at undergraduate level, and that depth is being sacrificed for breadth. Roberts also recommended that schools and Universities link more closely to facilitate a better transition to undergraduate programmes in science.

Thus there appears to be some mis-alignment between the expectations of academic staff in HE in the preparation prospective students are receiving in relation to this particular skill area. This hypothesis is contrary to the theory of constructivist learning (Bruner 1966), where students build new knowledge and understanding based upon what they have previously learned. Constructivist theory would therefore suggest that curricula and their content should be designed in such a way to allow students to build upon prior knowledge and experiences. It is hypothesised that the FE-HE interface with regard to written scientific communication skills may not articulate. In practice this has resulted in the provision of additional support for new University entrants to develop these skills, e.g. increased referral to the Academic Skills Unit at the University of Portsmouth.

The writing of scientific reports is a key aspect of the transition experience between FE and HE for BSc students. Student study habits formed in FE persist at least until the end of the first semester of University and this has implications for student retention and progression ((Lowe and Cook 2003). The teaching and assessment styles in many FE institutions have a tendency to develop a particular set of study skills and learning strategies, which are not always relevant to more independent styles of learning, and consequently diminishes the ability of new undergraduates to produce scientific based discourse in their report writing (Lowe and Cook 2003). Furthermore, it 
is acknowleged that the student experience in terms of developing scientific communication skills depends on context and will be affected by subject choice, school characteristics and the quality of delivery.

Critically, because A Level students tend to be guided through their courses they may not receive enough initial support at University in terms of the rules and conventions of scientific writing, analysis and critical thinking (Lowe and Cook 2003). This manifests itself in problems associated with citation, referencing and the increasing problem of plagiarism. Furthermore, there is a tendency for students to report science using informal language, in the first person and with a limited evidence base.

Changes in funding methodology, and the delivery and composition of the science curricula in secondary education have led to the finding that 'almost one in six schools has unsatisfactory accommodation for science' (HMI report 2005). This is mainly reflected in a reduction in practical opportunities, which consequently has resulted in students with a reduced set of practical competencies and less opportunity to write up practical reports.

In summary, our research question is to determine the approaches to scientific writing at FE and HE, the student experience of this transition and how the transition can be enhanced for the benefit of students. Specific objectives are: to gain a greater understanding of the approach to and preparation for scientific writing which currently exists in the FE sector; identify specific student perceptions and experiences of scientific report writing in both FE and HE contexts; determine the minimum standard of scientific communication skill levels expected by academics in range of science disciplines at the University of Portsmouth; and identify skill deficits in the transition from FE to HE. These findings will provide a basis to commence a dialogue between colleagues in the local FE and $\mathrm{HE}$ setting in relation to curricula development in this area and to develop evidence based interventions in which $\mathrm{HE}$ may need to adapt to accommodate the transition from FE to HE in terms of scientific communication.

\section{METHODS}

\section{Overview}

The study design is a mixed quantitative/qualitative using questionnaires and structured interviews. Questionnaires were administered to 178 Level 1 students in the Science Faculty; semi-structured interviews were held with 15 staff teaching in the Science Faculty at the University and 16 FE science lecturers from local colleges. Informed consent was obtained from each subject and kept on file.

\section{Procedures}

The work commenced with the design and piloting of interview schedules and questionnaires. A representative sample of Level 1 students across a range of BSc disciplines in the science faculty completed an initial questionnaire to determine their preparation in scientific writing before entering the University; and a subsequent questionnaire after receiving a mark and feedback on their first submitted laboratory report. Academic staff in the science faculty also participated in a structured interview to assess their expectations of what potential new undergraduate students should be able to demonstrate as a minimum standard and science based lecturing staff in local FE Colleges were interviewed to gain a pre-entry perspective.

The data was collated, coded and entered on to a spreadsheet (Microsoft Excel 2003) for ease of analysis. A variety of qualitative devices were used to present data along with Chi-Square Tests to assess relationships between selected categorical relationships. The analysis in this paper is concerned only with the student experience.

\section{RESULTS}

\section{The Student Perspective}

128 Level 1 undergraduate students from the Department of Sports \& Exercise Science (DSES) and the School of Pharmacy and Biomedical Science (SPBMS) completed both questionnaires which examined their 
experience in the development of scientific communication skills both prior to arrival at University and after their first marked laboratory report assignments. This formed the cohort of interest.

The profile of the cohort is presented in Table 1 .

Table 1: Characteristics of Student Cohort

\begin{tabular}{llll}
\hline Gender & Males: $42 \%$ & Females: $58 \%$ & $>26: 6 \%$ \\
Age: & $17-20: 87 \%$ & $21-25: 7 \%$ & Other: $11 \%$ \\
Entry Qualifications & A Level: $84 \%$ & BTec: $5 \%$ & \\
Department of Origin & DSES: $41 \%$ & SPBMS: $59 \%$ & \\
\hline
\end{tabular}

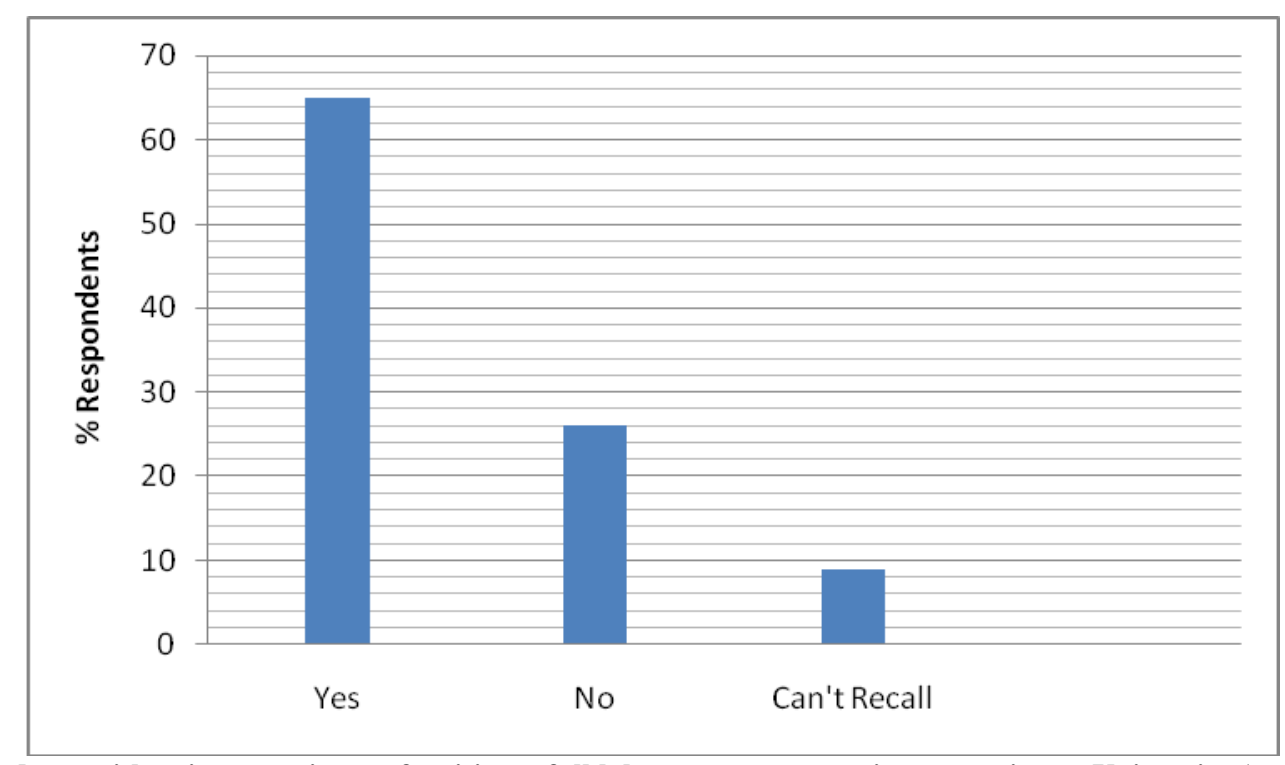

Figure 1: Students with prior experience of writing a full laboratory report prior to coming to University $(n=124)$

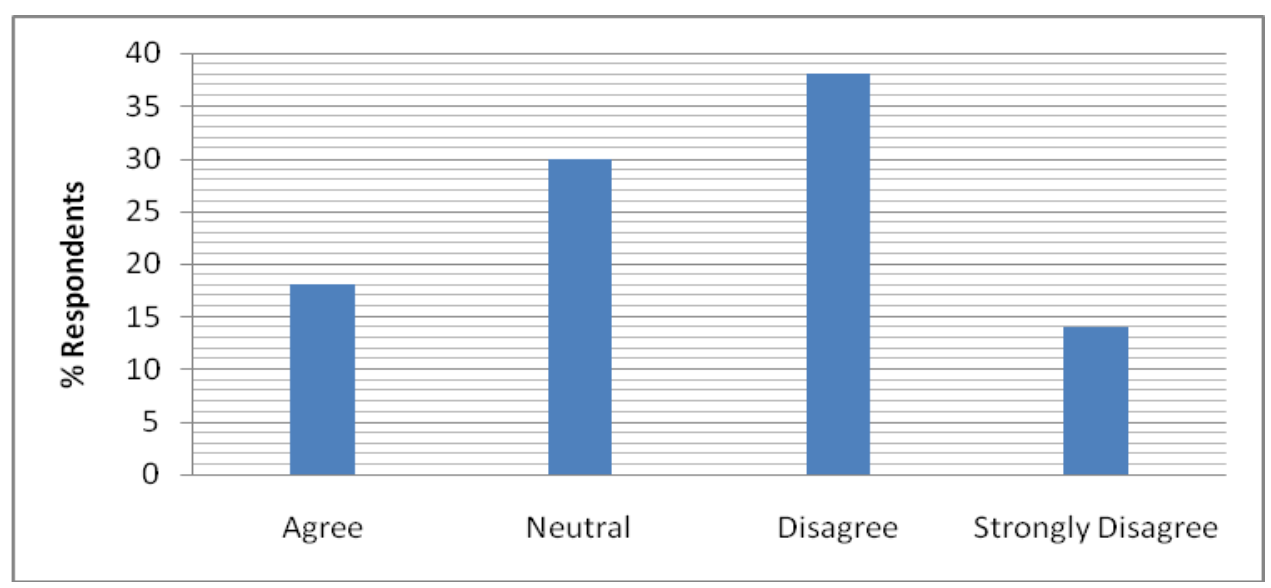

Figure 2: Student response to the question 'the preparation $I$ have received to write in a scientific manner prior to University has been adequate' $(n=127)$ 


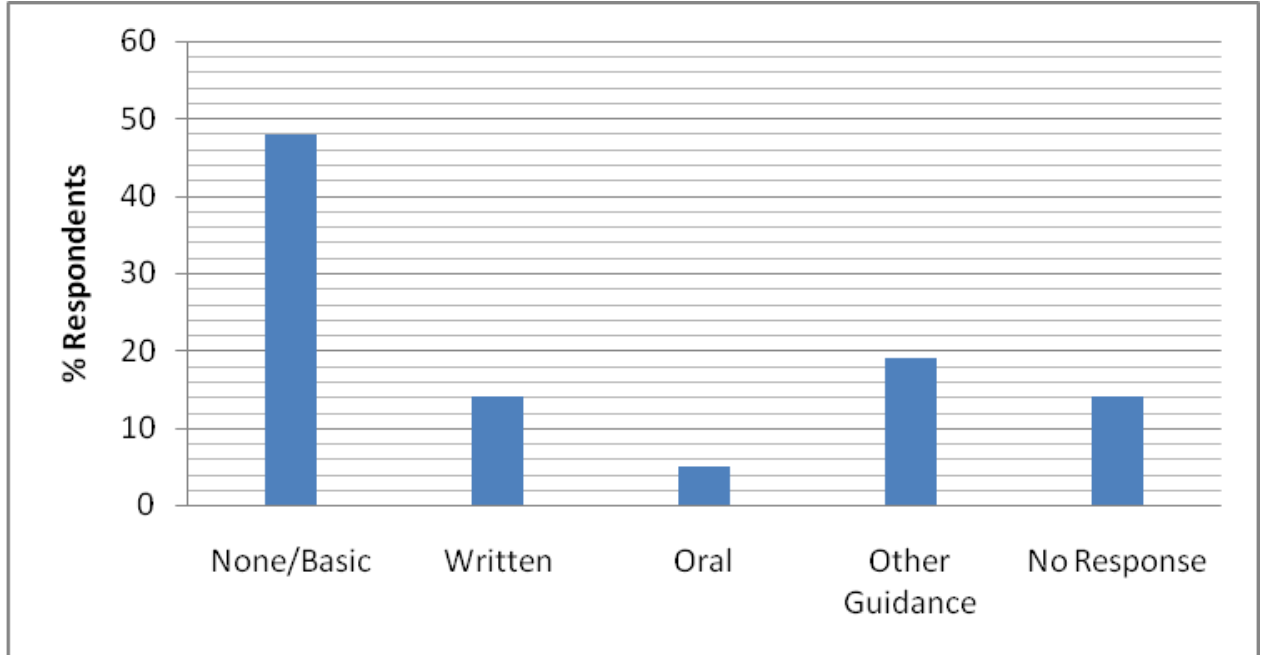

Figure 3: Training/guidance in writing in a scientific style provided to students before coming to University $(n=128)$

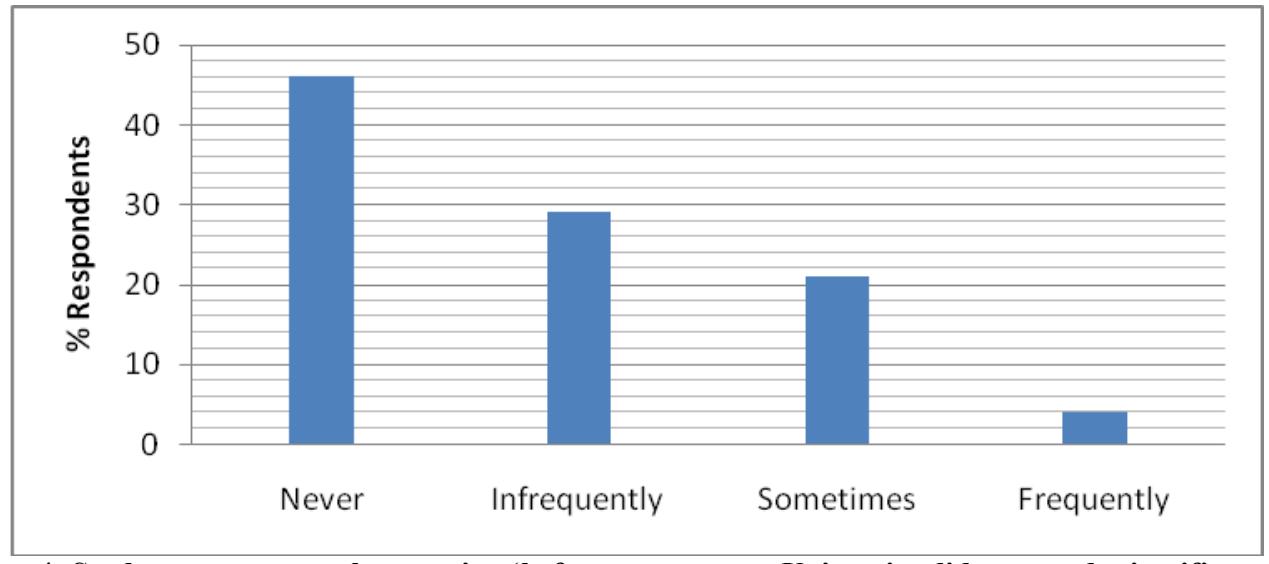

Figure 4: Student response to the question 'before you came to University did you read scientific articles (e.g., journal articles) in support of, or outside your FE studies?' $(n=126)$ 


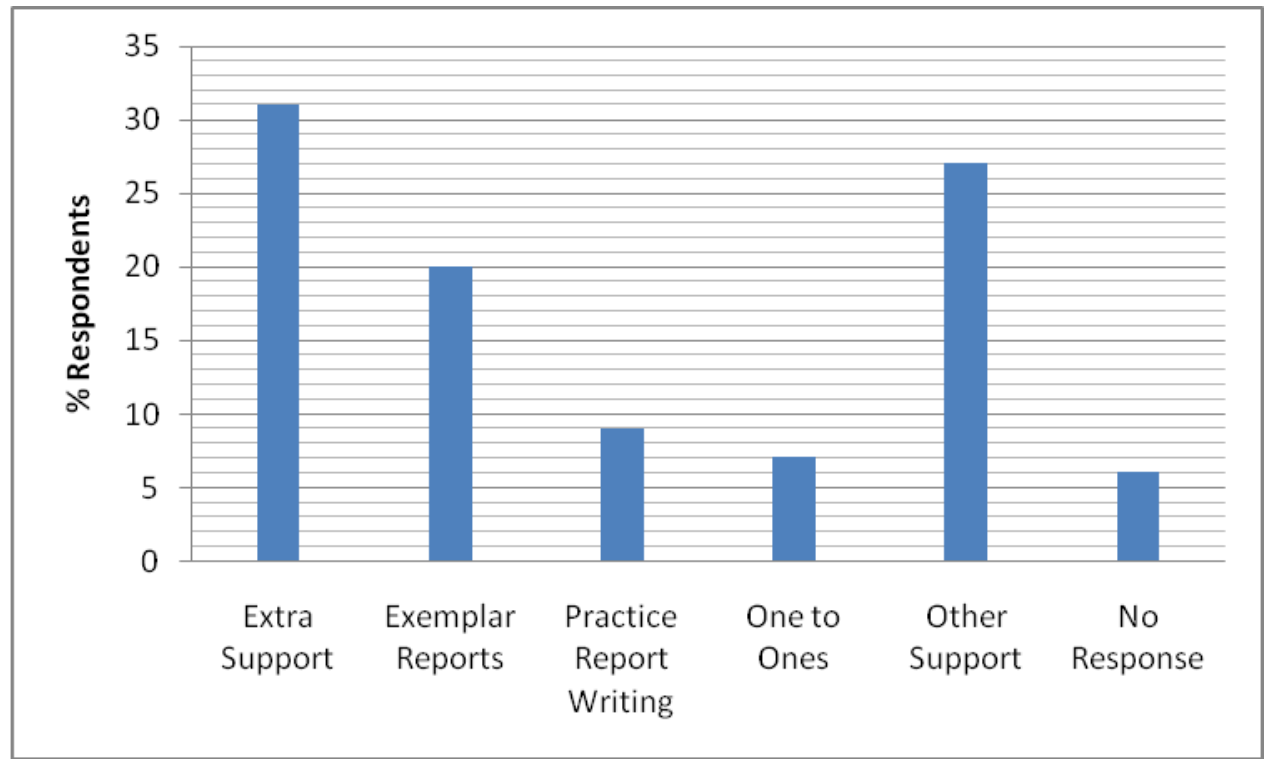

Figure 5: Student response on how training/guidance on scientific writing could be improved $(\mathrm{n}=128)$

Table 2 reports chi-square analysis in relation to student's prior experience of writing a formal laboratory report (categorised as Yes or No) before University, and its relationship in the context of the following statements:

1. I experienced significant problems in writing up my first laboratory report(s)

2. I I lelt confident about producing my first laboratory report

3. There is a big jump in the level of scientific writing expected between FE and University

Table 2: Chi-Square analysis of experience of scientific communication prior to University and aspects of their first laboratory report submission

\begin{tabular}{|c|c|c|c|c|c|}
\hline & & Yes & No & Chi-square & $P$ value \\
\hline \multirow[t]{4}{*}{ Statement 1} & Agree & 47 & 21 & & \\
\hline & Neutral & 18 & 8 & & \\
\hline & Disagree & 23 & 3 & & \\
\hline & & & & 3.88 & 0.143 (NS) \\
\hline \multirow[t]{4}{*}{ Statement 2} & Agree & 18 & 4 & & \\
\hline & Neutral & 25 & 8 & & \\
\hline & Disagree & 43 & 22 & & \\
\hline & & & & 2.36 & 0.307 (NS) \\
\hline \multirow[t]{4}{*}{ Statement 3} & Agree & 56 & 32 & & \\
\hline & Neutral & 14 & 0 & & \\
\hline & Disagree & 8 & 0 & & \\
\hline & & & & 11.3 & $0.004 *$ \\
\hline
\end{tabular}

* Statistical significant $(\mathrm{P}<0.05)$

Table 3 reports Chi-square analysis in relation to the home Department of the students (categorised as DSES or SPBMS) and the following:

1. Before coming to University, have you ever been required to write up a formal laboratory report which includes at least introduction, methods, results and discussion sections?

2 I experienced significant problems in writing up my first laboratory report(s)

3 I felt confident about producing my first laboratory report 
Table 3: Chi-Square analysis of student 'home' department and laboratory report exposure prior to University and aspects of their first laboratory report submission

\begin{tabular}{|c|c|c|c|c|c|}
\hline & & DSES & SPBMS & Chi-square & $P$ value \\
\hline \multirow[t]{3}{*}{ Statement 1} & Yes & 27 & 61 & & \\
\hline & No & 18 & 8 & & \\
\hline & & & & 10.92 & $0.0010 *$ \\
\hline \multirow[t]{4}{*}{ Statement 2} & Agree & 36 & 38 & & \\
\hline & Neutral & 9 & 18 & & \\
\hline & Disagree & 7 & 19 & & \\
\hline & & & & 4.58 & 0.1000 \\
\hline \multirow[t]{4}{*}{ Statement 3} & Agree & 6 & 14 & & \\
\hline & Neutral & 12 & 25 & & \\
\hline & Disagree & 34 & 36 & & \\
\hline & & & & 3.78 & 0.1500 \\
\hline
\end{tabular}

Table 4: Student perceptions and experience after submission of first laboratory report (Likert Scale: $1=$ Strongly Agree $2=$ Agree $3=$ Neutral $4=$ Disagree $5=$ Strongly Disagree)

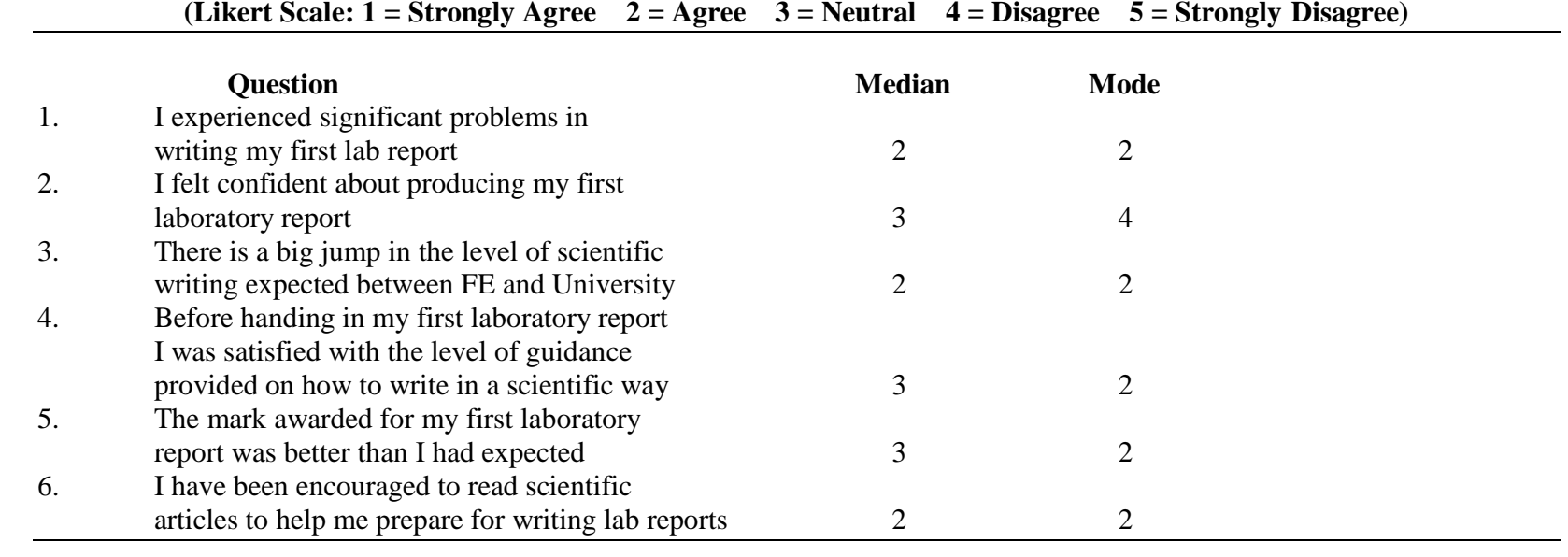

\section{DISCUSSION}

Anecdotally, it has been observed that students entering HE experience problems writing in a formal scientific style. This is particularly manifested in the production of laboratory reports. The purpose of the present study was to investigate the presence, nature and extent of these problems in a cohort of Level 1 students enrolled on BSc programmes in the faculty of science at the University of Portsmouth, UKI.

Although the findings suggest that a majority of students $(65 \%)$ produce a formal laboratory report consisting of introduction, methods, results and discussion sections before arriving at University (Figure 1), the data also suggests that the majority of students $(52 \%)$ reported that their preparation in the skills of scientific communication prior to University was inadequate (Figure 2). Furthermore, $48 \%$ reported having no or only basic guidance in scientific communication skills before arrival (Figure 3), whilst $74 \%$ of students never or infrequently read scientific articles pre-University to help develop scientific communication competence (Figure 4). These data suggest that preparation for the demands and expectations of writing scientifically at University is sub-optimal and tends to support the suggestion that a mis-match exists between the sectors in the context of scientific communication skills. This hypothesis is supported by comments from FE Lecturers and HE academic staff. The study suggests that although students are undertaking some practical work particularly in A Levels such as chemistry, physics and biology, there is often no requirement to write these up as formal reports. Where laboratory reports are written up, and the evidence suggests that at least one report is produced by the majority of new entrant students, it can only be speculated that this endeavour is tokenistic and understanding is limited. 
Students also suggest that the development of scientific communication skills at University is not without its problems. In particular the majority of students reported having issues with their first laboratory report; feeling unconfident about its production; confirming that there is a big jump in the level of scientific writing expected between FE and HE; and feeling ambivalent about the level of guidance and support provided by University tutors in the production of this initial laboratory report (Table 3).

Chi-square analysis investigated whether there were any relationships between student's prior exposure to writing a full laboratory report in FE and their experiences in writing up their first HE based report (Table 2). No relationships were found between prior exposure and the degree of problems associated with the first report or the level of confidence experienced about producing the report. However, there was a significant relationship $(\mathrm{P}<0.05)$ between prior exposure and the perceived 'jump' in level expected between FE and HE. This suggests that students with no prior experience of writing a full laboratory report in FE perceived a much more demanding transition in this skill area.

A further Chi-square analysis was performed to investigate whether there were any relationships between the host Department of the student (DSES vs SPBMS) and aspects of the laboratory report experience. It was hypothesised that students on programmes in SPBMS may experience fewer problems and report greater confidence in the production of their first laboratory report compared to students following programmes in DSES. This is because students enrolled on SPBMS tend to come in with a more traditional A level science preparation. The analysis confirmed that there was a significant relationship between a student's home department and whether or not they had been exposed to writing a formal laboratory report before coming to study at University. Specifically students studying on programmes in SPBMS reported greater exposure than students enrolled in DSES primarily because their A Level diet consisted of more traditional science subjects such as chemistry. However, despite this observation, the data showed no relationships between 'home department' and either reported problems in completing the first report or the level of confidence expressed in relation to the task. These data suggest that the prior exposure to writing a formal laboratory report before University had not affected perceptions, competence or confidence when it came to producing the first University based report. Again, this indicates that any potential useful progression from FE to HE in relation to scientific communication skills is blunted.

Modal data also confirms that students rank the discussion as the hardest element of a formal laboratory report, followed by the introduction and results sections. The methods were perceived as the easiest component. These data have implications for the teaching of science report writing and may suggest that greater emphasis and practice is placed on the development of discussion and critical analysis.

Overall it is our contention that there is a lack of 'joined-up thinking' between curricula designers in FE and $\mathrm{HE}$ to facilitate the transition needed for the development of scientific communication skills. There is less flexibility for FE colleagues to address this issue given that their programmes are nationally prescribed. Perhaps the emphasis is therefore on HE staff to re-adjust and adapt their expectations about the likely quality of initial laboratory reports and other scientific communication skills in new entrants. The Roberts review (2002) made this very point about Universities re-calibrating their teaching and curricula to the needs of new entrant students. It is questionable whether this advice has been heeded.

Therefore it is recommended that science based academics in HEIs recognise and reflect on the extent of this problem. They may then need to consider addressing this skills deficit by, for example, introducing an initial laboratory report which is formatively and rapidly assessed via the personal tutorial system. This enables students to receive qualitative feedback which can be used to address any shortcomings in advance of subsequent marked assignments. This would go some way to satisfying students demands for extra support, more practice in report writing and small group feedback in the development of these vital communication skills within a massified HE system. 


\section{REFERENCES}

1. $\quad$ Bruner, J. (1966), Towards a theory of instruction: Cambridge, MA, Harvard University Press.

2. HMI Report (2005), Ofsted Departmental Report (2005-06).

3. Roberts Review (2002), SET for success: the supply of people with science, technology, engineering and mathematics skills.

4. Lowe, H and Cook, A. (2003), Mind the gap: Are students prepared for higher education. Journal of Further and Higher Education, 27 (1), p53-76.

\section{NOTES}

